\title{
WORD-LEVEL AND PHRASE-LEVEL PREFIXES IN ZULU*
}

\author{
JOCHEN ZELLER
}

\begin{abstract}
This article investigates two strategies of relative clause formation in Zulu, a Bantu language spoken in South Africa. The standard way of forming a relative clause in Zulu involves a prefix (a so-called "relative concord") which is attached to the predicate of the relative clause. In this strategy, the relative concord expresses agreement with the subject of the relative clause. In a second strategy, the relative concord seems to be prefixed to the first word of the relative clause; in this position, it agrees with the head noun. The main claim of this article is that the second strategy of relative clause formation in Zulu is an example of phrasal affixation. I show that the relative concord does not merge morphologically with the first word of the relative clause, but is attached to the whole relative clause. Following Anderson (1992), I analyse this kind of phrasal affixation as an inflectional process; the relative clause is a predicate, and the relative concord in the second strategy expresses agreement between this phrasal predicate and the head noun.
\end{abstract}

\section{Introduction}

In Zulu, one of the nine officially recognised Bantu languages of South Africa, the predicate of a relative clause is usually modified with a prefix which expresses both relativisation and agreement with the subject of the relative clause (a so-called relative concord). However, there is a second strategy of relative clause formation in Zulu in which the relative concord seems to be prefixed to the initial noun of the relative clause. In this position, it no longer agrees with the relative clause subject, but with the head noun of the construction. This paper investigates these two different relative clause formation strategies in Zulu.

* I thank my former colleagues Dr Simon Donnelly, Dr Stefan Ploch and Dr Nhlanhla Thwala at the University of the Witwatersrand in Johannesburg for many helpful discussions, my Zulu informants for their time and patience, the two anonymous reviewers and the participants of the 10th International Morphology Meeting in Budapest and the ALASA-conference in Durban for their comments and suggestions. A special thanks goes to Dori Posel for her help with this article.

1216-8076/03/\$20.00 (c) 2003 Akadémiai Kiadó, Budapest 
In sections $\mathbf{2}$ and $\mathbf{3}$, the properties of the two strategies are outlined and discussed. I assume that the relative concord in the first strategy is a word-level prefix which morphologically combines with the predicative stem of the relative clause. I then argue in section $\mathbf{4}$ that the relative concord in the second strategy is prefixed to the relative clause as a whole. Following a proposal articulated in Anderson (1992), I analyse this kind of "phrasal affixation" in terms of cliticisation. I assume that the relative marker in these constructions is a clitic which uses the initial noun of the relative clause as its phonological host. In section $\mathbf{5}$ I suggest that the relativising phrasal affix of the second strategy represents an intermediate stage of a grammaticalisation process that derived the relative concord of the first strategy from an earlier relative clause construction in Zulu which used relative pronouns.

\section{Relative concords in Zulu}

Zulu is part of the Nguni group of languages spoken in South Africa. As in other Bantu languages, each noun in Zulu belongs to a particular noun class. Class membership determines agreement with nominal modifiers, verbs, adjectives etc. In a normal declarative sentence, a prefix is attached to the verbal stem which expresses agreement with the subject: ${ }^{1}$

(1) (a) Abafana ba-sebenza esitolo

boy2 sp2-work in.shop7

'The boys are working in the shop.'

(b) Isitshudeni si-funda incwadi

student7 sp7-read letter9

'The student is reading the letter.'

(c) Izintombi zi-dlala ne-ngane

girl10 sp10-play with-child9

'The girls are playing with the child.'

1 In the glosses, I mark the noun classes and agreement through numbers, according to Meinhof's (1906) numbering system of Proto-Bantu. Morphemes are glossed as follows: apl $=$ applicative, cop $=$ copula, def $=$ sentential definitiser, dem $=$ demonstrative pronoun, det $=$ determiner, fem $=$ feminine gender, foc $=$ focus marker, fut $=$ future tense, masc $=$ masculine gender, neg $=$ negation, neut $=$ neuter gender, oc $=$ object clitic, pass $=$ passive, $\mathrm{pc}=$ pronominal clitic, perf $=$ perfect tense, $\mathrm{pl}=$ plural, poss $=$ possessive marker, $\mathrm{rc}=$ relative concord, $\mathrm{refl}=$ reflexive clitic, $\mathrm{rel}=$ relative complementiser, $\mathrm{rp}=$ relative pronoun, $\mathrm{rs}=$ relative suffix, $\mathrm{sg}=$ singular, $\mathrm{sp}=$ subject prefix, tns $=$ Tense. 
In relative clauses, the form of the initial prefix which is attached to the verb stem changes. The verb is now prefixed with a so-called relative concord (cf. Doke 1954), printed in boldface in the examples that follow. As the examples in (2) and (3) show, the relative concord always agrees with the subject of the relative clause; relativisation and subject agreement are simultaneously expressed by the relative concord: ${ }^{2}$

(2) (a) Abafana [aba-sebenza esitolo] ba-fik-e namhlanje boy2 rc2-work in.shop sp2-arrive-perf today 'The boys who work in the shop arrived today.'

(b) Incwadi [esi-yi-funda-yo isitshudeni] in-de letter9 rc7-oc9-read-rs student7 sp9-long 'The letter that the student is reading is long.'

(c) Ingane [ezi-dlala na-yo izintombi] i-ya-hleka child9 rc10-play with-pc9 girl10 sp9-foc-laugh 'The baby with whom the girls play is laughing.'

The examples in (2) illustrate that the relative concords in Zulu are the result of combining the subject prefix of the respective noun class with a relative morpheme whose underlying form is $a_{-}$. The overt phonological form of the relative morpheme is determined by a general rule of Vowel Raising that causes the vowel $a$ - to assimilate in height and backness to the high vowel of the following subject prefix (cf. e.g., Khumalo 1992; van der Spuy 2001), deriving the two allomorphs $o$ - and $e$-. If the subject prefix starts in a consonant, as in the examples in (2), the relative concord has the form relative morpheme + subject prefix. However, if the subject prefix is a vowel, it is deleted. ${ }^{3}$ In noun classes with vowel subject prefixes, the relative concord therefore only consists of the relative morpheme:

(3) (a) Umfana [o-sebenza lapha] u-ya-gula

boy1 rc1-work here sp1-foc-be.sick

'The boy who works here is sick.'

(b) Ukudla [ugogo a-ku-pheka-yo] ku-mnandi impela food14 granny1a rc1a-oc14-cook-rs sp14-tasty indeed 'The food that granny cooks is tasty indeed.'

2 The subjects of the relative clauses in (2b) and (2c) are extraposed. Subject extraposition in relative clauses of this type is not compulsory in Zulu; however, it is the preferred option for some speakers (cf. e.g., Du Plessis-Visser in prep.).

3 If a high vowel subject prefix is followed by a vowel-commencing morpheme, the former is replaced by a glide, cf. Khumalo (1992). 
(c) Incwadi [e-fund-wa yi-sitshudeni] in-de letter9 rc9-read-pass by.student7 sp9-long

'The letter that is being read by the student is long.'

In the examples in (2a), (3a) and (3c), the head noun corresponds to the subject of the relative clause. Following Doke (1954), I refer to these constructions as direct relatives. When the head noun corresponds to some other constituent in the relative clause, as in (2b), (2c) and (3b), the construction is called an indirect relative. In indirect relatives, the grammatical function of the head noun is indicated through a pronominal clitic inside the relative clause (underlined in (2) and (3)). In (3b), for example, the head noun corresponds to the object of the verb, and hence, an object clitic which agrees with the head noun is attached to the verb stem. In (2c), the head noun corresponds to the object of the prepositional prefix $n a-$ 'with', and the clitic appears adjoined to the preposition. The verb of a relative clause in $\mathrm{Zulu}$ occurs in the so-called participial mood which is taken to express subordination (cf. Doke 1954). Furthermore, a relative suffix is usually attached to the predicate of the relative clause when it occurs in phrase-final position, (2b) and $(3 \mathrm{~b})$. Another interesting observation that can be made with respect to relative concords is that they strongly resemble the Zulu demonstrative pronouns of the so-called first position (whose meanings correspond to English this and these). The only surface difference is that the initial lateral consonant of the demonstratives is lost with the relative concords. ${ }^{4}$ (I come back to this observation in section 5.1.) Table 1 lists the full paradigm of relative concords in relation to subject prefixes and demonstratives.

In the following I adopt the terminology introduced in Poulos (1982) and refer to this way of forming relative clauses in Zulu as "Strategy 1".

\section{Strategy 2}

Zulu grammars and textbooks present an alternative way of forming relative clauses. When the head noun corresponds to a possessor in the relative clause, it seems possible to attach the relative concord to the initial noun of the relative clause (cf. (4)-(7)):

4 Notice that in Swati, another Nguni language, relative concords have also maintained the initial consonant. Therefore, relative concords and demonstrative pronouns are identical in Swati. 
Table 1

Subject prefixes, demonstratives and relative concords in Zulu

\begin{tabular}{|c|c|c|c|}
\hline NOUN CLASS & SUBJECT PREFIX & RELATIVE CONCORD & $\begin{array}{c}\text { 1ST POSITION } \\
\text { DEMONSTRATIVE }\end{array}$ \\
\hline \hline $1,1 \mathrm{a}$ & $\mathrm{u}-$ & $\begin{array}{c}\text { O- (direct relatives) } \\
\text { a- (indirect relatives) }\end{array}$ & lo- \\
\hline $2,2 \mathrm{a}$ & $\mathrm{ba}-$ & aba- & laba \\
\hline 3 & $\mathrm{u}-$ & o- & lo \\
\hline 4 & $\mathrm{i}-$ & e- & leli \\
\hline 5 & $\mathrm{li}-$ & eli- & la(wa) \\
\hline 6 & $\mathrm{a}-$ & $\mathrm{a}-$ & lesi \\
\hline 7 & $\mathrm{si}-$ & esi- & le \\
\hline 8 & $\mathrm{zi}-$ & ezi- & lezi \\
\hline 9 & $\mathrm{i}-$ & e- & lolu \\
\hline 10 & $\mathrm{zi}-$ & ezi- & lobu \\
\hline 11 & $\mathrm{lu}-$ & olu- & loku \\
\hline 14 & $\mathrm{bu}-$ & oku- & \\
\hline 15 & $\mathrm{ku}-$ & & \\
\hline
\end{tabular}

(4) umfazi [o-bantwana ba-khe u-ba-limaz-ile] woman1 rc1-child2 poss2-pc1 2sg-oc2-hurt-perf 'the lady whose children you hurt'

(5) Si-zo-theng-ela entsha ikhehla [eli-mbazo ya-lo i-lahlek-ile-yo] 1pl-fut-buy-apl new.one old.man5 rc5-axe9 poss9-pc5 sp9-be.lost-perf-rs 'We shall buy the old man whose axe is lost a new one.'

(Ziervogel et al. 1985, 225)

(6) umuntu [o-'zandhla za-ke zi-mhlope] person1 rc1-hand8 poss8-pc1 sp8-white 'the person whose hands are white'

(Colenso 1859, 48)

(7) amakosi [a-'masimu a-wo si wa bona-yo] chief6 rc6-field6 poss6-pc6 1 pl oc6 see-rs 'the chiefs whose fields we see'

(uNemo no date; 19th century, 114)

5 The relative concord of class 1/1a in direct relatives seems to be based on the indicative subject prefix of class $1 / 1 \mathrm{a}$, which is $u$-, whereas the relative concord of class 1 in indirect relatives seems to be based on the subject prefix of the participial mood, which is $a$-.

6 The example in (7) illustrates that the first orthographers of Zulu used a much more disjunctive form of writing than the one which is used in present-day Zulu. Many morphemes were written as separate words (cf. van der Spuy 2001). 
Poulos (1982) provides more examples illustrating the properties of this construction which he labels "Strategy 2" (cf. Poulos 1982, 172):

(8) (a) Indoda [e-baba u-shay-e izinja za-yo] i-thukuthele man9 rc9-father1a sp1a-hit-perf dog10 poss10-pc9 sp9-be.angry 'The man whose dogs my father hit is angry.'

(b) INgisi [eli-baba u-hlala endlini ya-lo] li-ya-vilapha Englishman5 rc5-father1a sp1a-stay in.hut9 poss9-5 sp5-foc-be.lazy 'The Englishman in whose hut my father is staying is lazy.'

The examples show that in Strategy 2, the relative concord is no longer attached to the verb, but to the initial noun of the relative clause. This initial noun is usually the subject, as in the examples (5), (6) and (8). However, in (4) and (7), the object of the relative clause has been preposed, and consequently, the relative concord combines with the object noun. Importantly, the "misplaced" relative concord no longer agrees with the subject, but with the head noun (note that e.g., in (8b), we get class 5 eli-, not class 1a $o$ - or $a$-). When combined with the relative concord, the subject noun loses the initial vowel (sometimes called the augment or prevowel) of its class prefix. Whereas some grammars list Strategy 2 as the only way to form relative clauses with possessors, others mention both Strategy 1 and Strategy 2 as acceptable constructions for possessive relative clauses. For example, Poulos $(1982,171)$ presents (9) as a possible alternative to (8a):

(9) Indoda [ubaba a-shay-e izinja za-yo] i-thukuthele man9 father1a rc1a-hit-perf dog10 poss10-pc9 sp9-be.angry

'The man whose dogs my father hit is angry.'

(9) is the Strategy 1-variant of (8a). The relative concord is attached to the verb and expresses agreement with the subject. Poulos (1982) argues that Strategy 2 is also found with other kinds of indirect relatives. (10a) illustrates Strategy 1 with a relative clause construction whose head noun corresponds to the direct object; (10b) expresses the same grammatical relation by means of Strategy 2 (cf. Poulos 1982, 119):

(10) (a) Indoda [ubaba a-yi-thanda-yo] i-y-inkosi chief9 father1a rc1a-oc9-love-rs sp9-cop-chief9

(b) Indoda [e-baba u-ya-yi-thanda] i-y-inkosi man9 rc9-father1a sp1a-foc-oc9-love sp9-cop-chief9

'The man whom father likes is a chief.'

In the following example, from van der Spuy $(2001,56)$, the head noun corresponds to the complement of a preposition: 


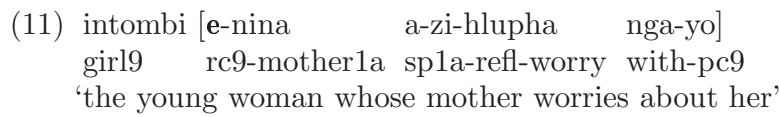

In Strategy 2, it seems no longer compulsory to mark the relative clause as a subordinate clause. Recall that in Strategy 1, the relativised verb would always appear in the participial mood. In contrast, the verb of a relative clause in Strategy 2 may occur in the indicative, and usually appears without the relative suffix. ${ }^{7}$

It must be noted that Strategy 2 is not fully acceptable for all Zulu speakers. Many of my informants considered the examples in (4)-(11) "bad Zulu", clumsy, or even ungrammatical; Strategy 1 was generally preferred (I come back to this point in section 5.2). The responses, however, were quite diverse. Some Zulu speakers accepted the examples from Strategy 2 that are found in the literature, others accepted them with minor changes. For example, some of my informants did not accept the example in (12a), where the verb appears in the indicative mood, but they found that the example improved when the verb morphology followed that in Strategy 1 (i.e., participial subject prefix and relative suffix), (12b):

(12) (a) inkosi [e-mntwana wa-yo u-ya-gula] chief9 rc9-child1 poss1-pc9 sp1-foc-be.sick 'the chief whose child is ill'

(b) inkosi [e-mntwana wa-yo a-gula-yo] chief9 rc9-child1 poss1-pc9 sp1-be.sick-rs 'the chief whose child is ill'

Some speakers detected interesting semantic differences between Strategies 1 and 2. In (9), which is the Strategy 1-variant of (8a), the subject of the relative clause $u b a b a$ was interpreted as referring to the speaker's father. However, in (8a), where the subject is modified with the relative concord (ebaba), it was taken to be more closely related to the head noun; my informants interpreted this as 'the man's father' (or as 'the Englishman's father' in (8b)). Example (11) reflects the same situation; although there is no possessive pronoun, the subject of the relative clause is interpreted as standing in a possessive

7 The data are not clear in this respect. In most examples in Strategy 2, the indicative subject prefix is attached to the verb stem (cf. e.g., $u$ - (class 1/1a) in (8a)). However, one also finds examples where the participial subject prefix appears instead (cf. e.g., $a$ (class 1/1a) in (11) and in (12b) below). In Xhosa, another language of the Nguni group which forms relative clauses by the same two strategies found in Zulu, the relative suffix -yo occurs regularly in both Strategy 1 and Strategy 2 (cf. Pahl 1983). 
relation to the head noun. Furthermore, some of my informants observed that Strategy 2 occurs more often in idiomatic expressions such as (13):

(13) Insizwa [e-ntombi zi-yi-celukhisi] a-yi-kho namhlanje

young.man9 rc9-girl10 sp10-oc9-ask.for.kiss neg-sp9-be.here today

'The charming young man is not here today.'

Literally: 'The man from whom the girls ask a kiss is not here today'.

I do not address the semantic implications of Strategy 2. Rather, I want to account for the observation that the relative concord in Strategy 2 combines with the first word of the relative clause. In the next section, I discuss some problems with the idea that the relative concord in Strategy 2 is morphologically affixed to the initial noun of the relative clause. I offer an alternative explanation which treats the relative concord in examples like (4)-(13) as a "phrasal affix".

\section{Clitics and phrasal affixation}

One might conclude from the data discussed in section 3 that Strategy 2 involves the prefixation of a relative concord to an adjacent noun stem. In this section I present some conceptual problems with this view and suggest an alternative proposal. I argue that the relative concord in Strategy 2 does not form a morphosyntactic word with the initial noun of the relative clause. Rather, I suggest that the relative marker in this construction is a clitic which is prefixed to the whole relative clause.

\subsection{The problem: predication and agreement}

In Strategy 1, the relative concord is a genuine prefix; it is an inflectional morpheme which is attached to the predicate of the relative clause (which can be a verb or an adjective). If the merging of the relative concord and the noun observed in Strategy 2 was the same morphological process which combines a prefix and a stem on the word level, then one would have to conclude that relative concords can also attach to nominal stems. But then we would expect to find relative clauses like (14a):

(14) (a) *Indoda [e-baba] i-hamb-ile. man9 rc9-father1a sp9-go-perf 
(b) Indoda [e-ng-ubaba] i-hamb-ile man9 rc9-cop-father1a sp9-go-perf 'The man who is a father has left.'

(14) shows that if a nominal predicate is used in a relative clause, it is not possible to simply attach a relative concord directly to the nominal stem, (14a). Instead, the insertion of a copula affix is required, (14b). But if a relative concord cannot attach to a nominal predicate in Strategy 1, why can it apparently be affixed to a noun in Strategy 2?

A related question arises from the observation that the relative concord in Strategy 2 establishes agreement with the head noun. Agreement is usually determined by specific syntactic contexts. If one really wanted to argue that the relative marker in Strategy 2 expresses agreement between the head noun and the subject of the relative clause, then it would need to be stipulated that an element in subject position can agree with an NP outside its clausal projection. This kind of long distance agreement between two nouns is itself not unproblematic, but suppose a reasonable analysis could be presented for the agreement between head noun and relative clause subject in Strategy 2. Then the next problem is raised immediately by constructions like (4) and (7), where the agreement marker is not attached to the subject, but to a fronted object noun. If one did not want to claim that a fronted object occupies the canonical subject position (a claim which would be difficult to substantiate), then yet another stipulation would need to be made to account for the fact that agreement can also be expressed between a fronted object and the head noun.

In the light of these problems, it seems that an alternative analysis is called for which does not treat the relative marker in Strategy 2 as a wordlevel prefix which combines with a nominal stem.

\subsection{The solution: relative markers as phrase-level affixes}

When a relative concord in Strategy 1 attaches to a verb or an adjective in the relative clause, it expresses a predication relation between this predicate and the subject which is overtly marked by agreement. The relative marker in Strategy 2 agrees with the head noun, but neither the subject of the relative clause nor a fronted object can possibly be interpreted as predicates. Obviously, it is not the initial noun of the relative clause which is the predicate, but rather the whole relative clause itself. Relativisation turns a sentence into a "complex adjective" (cf. Quine 1960) which forms a complex predicate with the head noun (cf. Partee 1975; Heim-Kratzer 1998; Rebuschi 2002). In 
the light of this observation I propose that the relative marker in Strategy 2 attaches to the whole relative clause. Like the relative concord of Strategy 1, it attaches to a predicate, but in contrast to Strategy 1, the relevant predicate is not a word, but a phrase. This means that I analyse the relative marker in Strategy 2 as a "phrasal affix".

Anderson (1992) argues that besides inflectional word-level morphology, there is also "inflectional morphology of phrases". Like inflectional word formation rules, which may change the phonological form of a host by attaching an inflectional affix to a word stem, the rules of phrase-level morphology may require affixes to attach to a phrasal host, depending on the phrase's morphosyntactic feature specification. The standard case of phrasal inflection discussed by Anderson is cliticisation. Clitics are affixes that are added as overt manifestations of a morphological rule that operates on phrases. ${ }^{8} \mathrm{~A}$ wellknown example of such a phrasal affix is the English possessive clitic 's:

(15) (a) [a friend of mine]'s book

(b) [a man I know]'s hat

(Lieber 1992, 14)

(c) I once knew[that guy you're talking about]'s brother in law

(Anderson 1992, 212)

Although the syntactic and semantic scope of the possessive marker is the whole preceding noun phrase, the clitic is attached only to the last word of the respective noun phrase (cf. Marantz 1988; Halpern 1995). Anderson (1992) and Lieber (1992) therefore analyse 's as an inflectional phrasal affix which realises a morphological property of the preceding noun phrase, the feature [+possessive]. The clitic does so by attaching to the last word of this phrase, regardless of the syntactic category of that word.

I adopt these considerations for my analysis of Strategy 2 in Zulu relatives. Whereas the phrase-final morpheme in English possessives is a phrasal suffix, the relative marker in Strategy 2 can be regarded as a phrasal prefix.

8 Zwicky (1977) distinguishes between two kinds of clitics, viz. simple and special clitics. A simple clitic is the phonologically reduced form of an independent word; it belongs to the same syntactic category as this word and appears in the same syntactic position in which the full word would be licensed. For example, the reduced form of the auxiliary is in How's your old man? is a simple clitic. In contrast, a special clitic appears in a syntactically "unexpected" position which is determined by a special clitic-rule. Anderson (1992) adopts Zwicky's distinction and only analyses special clitics as phrasal affixes; he treats simple clitics merely as phonologically "weak" lexical items. Furthermore, Anderson (1992) argues that next to special clitics with properties of inflectional affixes, there are also derivational phrasal affixes, i.e., special clitics that introduce a change of meaning or discourse function of the phrase with which they combine. For more details of Anderson's classification, I refer the reader to Anderson (1992, chapter 8). 
What looks like a relative concord affixed to the initial noun of the relative clause is in fact a phrasal affix which formally expresses agreement between the relative clause and the head noun.

The phrase-level inflection of relative clauses illustrated by Strategy 2 in Zulu corresponds to the word-level inflection of adjectives which agree with their nouns in languages like German:

(16) (a) eine stark-e Frau

det.fem strong-fem woman.fem

'a strong woman'

(b) ein stark-er Mann

det.masc strong-masc man.masc

'a strong man'

(c) ein stark-es Mädchen

det.neut strong-neut girl.neut

'a strong girl'

Like relative clauses, adjectives form complex predicates with the nouns they modify. Predicate conjunction is reflected by the agreement between the adjectival and the nominal predicate. Similarly, there is agreement between the conjoined predicates in Zulu relative clauses formed by Strategy 2. Since one of these predicates is a full clause, these agreement properties must be expressed by means of a phrasal affix. ${ }^{9}$

In the light of Anderson's (1992) theory, the phrasal affix of Strategy 2 must be analysed as a clitic, and the examples provided in section 3 confirm this conclusion. Like all clitics, the relative marker is phonologically dependent on a host. It cannot stand alone, but must form a phonological unit with the following word, and it cannot be displaced by syntactic movement rules. This creates the illusion that the relative marker in Strategy 2 is a relative concord affixed to a noun stem. However, in contrast to genuine word-level affixes, clitics do not depend on particular hosts, but "exhibit a low degree of selection with respect to their hosts" (Zwicky-Pullum 1983, 503). The relative marker in Zulu must combine with the first word of the phrase to which it is affixed, and usually, this first word is the subject of the relative clause. Therefore, the relativising clitic is most frequently found phonologically attached to the subject noun. However, if some other constituent appears in the first position of the relative clause, then it combines with the first word of that

9 In a similar spirit, Poulos $(1982,124)$ notes that "it appears as though there is a tendency in Zulu to bring the whole RC [= relative clause] into 'subjectival agreement' with the ANT [= the head noun]". However, Poulos does not elaborate on this observation. 
constituent. For instance, if an object is fronted, as e.g., in the examples (4) and (7) above, the clitic and the subject noun are no longer adjacent. Since the relative marker attaches to whatever element appears immediately to its right, it combines with a non-subject noun in these contexts. Furthermore, in contexts in which the relative clause predicate is the first element of the relative clause (as is the case, for example, in direct relatives), the relative marker combines with a verb or adjective (I return to this point in section 5.2). This selectional freedom of the relative marker strongly supports the view that it is a clitic, i.e., a phrasal affix attached to the relative clause.

Possibly, another property of Strategy 2 discussed in section 3 also follows from this analysis. The difference between the morphological form of the predicates in Strategy 1 and Strategy 2 can now be accounted for by the assumption that the dependency of a relative clause in Zulu must be marked in one of two possible ways. The first option is to mark the relative clause as a predicate by means of a phrasal affix which agrees with the head noun. In that case, the relative clause itself can occur in the indicative, as is possible in Strategy 2. Alternatively, if no phrasal affix is present, the dependent status of the relative clause must be expressed via subordination. Therefore, the relative clause must occur in the participial mood in Strategy 1. An elaboration of this idea would require a more careful study of the semantics of relative constructions in Strategy 1 and Strategy 2 than I can provide here, but it is certainly an interesting hypothesis which might stimulate future work.

\section{Relative pronouns, relative clitics and relative concords in Zulu}

\subsection{Strategy 2 and relative pronouns}

In Anderson's (1992) theory, the rules of phrase-level morphology operate on the phonological form of a phrase and its morphosyntactic feature specification, mapping it onto the morphophonological form of the inflected phrase. According to this view, a phrasal affix is just a phonological reflex of the application of a particular morphological (phrase-level) rule. This means that one would not have to postulate a specific syntactic position for the relative marker in Strategy 2 in Zulu; its status would be purely phonological. However, although I indeed assume, following Anderson, that the clitic which is prefixed to Zulu relative clauses is not associated with a particular structural position, I suggest that it has been derived historically from a syntactically 
independent element. The assumption that I want to defend here is that the relative marker in Strategy 2 is derived from a relative pronoun.

Relative pronouns typically agree with their head nouns in languages like German or English:

(17) (a) der Mann [den ich gesehen habe] the man-sg rp-sg I seen have 'the man whom I have seen'

(b) die Männer [die ich gesehen habe] the men-pl rp-pl I seen have 'the men whom I have seen'

(18) (a) the man [whom I have seen] [+human] rp-[+human]

(b) the $\operatorname{dog}$ [which I have seen] [-human] rp-[-human]

Following standard assumptions, I assume that relative pronouns are located in SpecCP of the relative clause (cf. e.g., Chomsky 1986; Heim-Kratzer 1998; Alexiadou et al. 2000). From this position, they can express agreement with the head noun (cf. Kayne 1994 for a proposal which captures this agreement relation through the assumption that the head noun and the relative pronoun form one constituent). I now suggest that the relativising clitics found in Strategy 2 in Zulu are the result of a grammaticalisation process that turned relative pronouns into phrasal affixes. As relative pronouns, the relative markers were independent elements that occupied SpecCP and agreed with the head noun, but because of their adjacency to the relative clause IP, they became reanalysed as phrasal affixes. As such, they still express agreement with the head noun, but no longer because of their structural position, but because they reflect the output of a morphological rule.

The idea that the phrasal affixes in Zulu are based on relative pronouns is supported by typological evidence. Recall that the Zulu relative concords, which are identical in form to the phrase-level affixes of Strategy 2, bear a striking resemblance to the demonstrative pronouns in Zulu (cf. Table 1 in section 2). Importantly, demonstrative pronouns are used as relative pronouns in many Bantu languages, cf. the following examples: ${ }^{10}$

10 The original examples do not always give glosses. I have added them as far as I could determine the basic morphological structure. Notice that example (23) from Ngemba shows that the demonstrative pronoun is in fact a relative pronoun in SpecCP (and not a relative complementiser in $\mathrm{C}^{0}$ ), since the demonstrative co-occurs with the relative complementiser bah. 
(19) tihomu [leti ti-dya-ka]

ox10 dem10 sp10-eat-rel

'cattle which eat'

(20) ngwana [eo nkgono a mo fepa-ng] child1a dem1a grandmother1a part1 oc1a feed-rs 'the child whom the grandmother feeds'

(Southern Sotho; Mischke 1998, 108)

(21) dijo [tse bana ba di jel-e-ng]

food8 dem8 child2 sp2 oc8 eat-past-rs

'the food which the children ate'

(Tswana)

(22) ulume [una ufeko a-mola] wa-yongola okulya

man dem girl1 sp1-saw sp1-wanted to.eat

'The man whom the girl saw wanted to eat.'

(23) nyung [wá bah a-keshung-ne mung wa la] a-kung atsang

man dem rel sp+tns-beat-rs child det def sp-enter into.prison

'The man who beat the child went to prison.'

(Ngemba; Chumbow 1977, 290)

I assume that the basic syntactic structure of relative clauses in early Zulu was the same as the structure of the relative clauses in (19)-(23). A demonstrative pronoun was used as a relative pronoun and therefore located in SpecCP from where it expressed agreement with the head noun. This relative pronoun was then reanalysed as an inflectional clitic which functions as a phrasal affix attached to the relative clause-IP.

Further support for this assumption is provided by one of my Zulu informants. She did not accept the Strategy 2-example in (11) (repeated in (24) for convenience), but instead suggested the construction in (25):

(24) intombi [e-nina a-zi-hlupha nga-yo]

girl9 rc9-mother1a sp1a-refl-worry with-pc9

'the young woman whose mother worries about her'

(25) intombi [le unina a-zi-hlupha nga-yo]

girl9 dem9 mother1a sp1a-refl-worry with-pc9

'the young woman whose mother worries about her'

The initial element in (25) is a demonstrative pronoun, not the relative marker, as illustrated by the fact that its form is $l e$, not $e-$. As such, it precedes the subject of the relative clause and agrees with the head noun, like the demonstrative pronouns in the examples in (19)-(23). According to my analysis, (25) reflects the relative pronoun-stage of early Zulu; the demonstra- 
tive pronoun le is located in SpecCP and therefore is adjacent to the IP. This adjacency has led speakers to reanalyse the pronoun as a phrasal affix.

The following observation creates room for some speculations about the factors that triggered the reanalysis of constructions like (25). Recall that in Strategy 2, the augment of the initial noun of the relative clause is deleted. Interestingly, the initial vowel of a noun is also deleted if a demonstrative pronoun in Zulu precedes the noun:

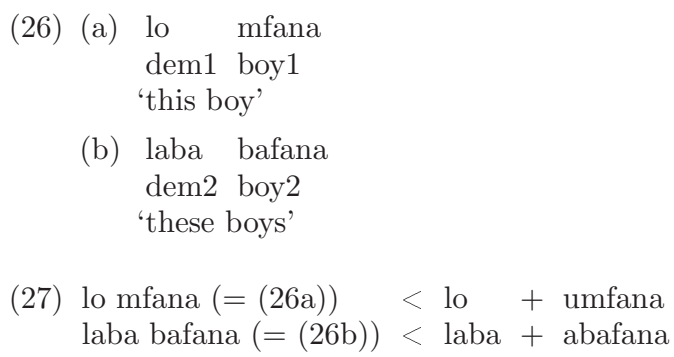

The deletion of the augment in (26) is probably related to the fact that this vowel has properties of a definite determiner (and therefore would be incompatible with a preceding demonstrative). As a result of prevowel deletion, the demonstratives in (26) cliticise to their following nouns; a noun and a preceding demonstrative form a phonological word (cf. Cope 1984; van der Spuy 2001). Now suppose that Strategy 2 is the result of an overgeneralisation of the rule that deletes the noun's initial vowel after a demonstrative. Some speakers would have applied the rule that triggers the deletion of the prevowels in (26) to examples like (25) and delete the augment of the first noun of the relative clause IP (because this noun is also preceded by a demonstrative (= relative) pronoun). Since nouns in Zulu usually need a prevowel, the relative pronoun was then forced to cliticise to the noun, as if to "take over" the place previously occupied by the augment. This phonological process was then functionally interpreted as the affixation of an agreement marker to the whole relative clause IP.

\subsection{Strategy 2 and relative concords}

Let me now turn to the question of how the relative markers of Strategy 2 in Zulu are related to the relative concords that function as genuine inflectional prefixes in Strategy 1. After all, the form of these elements is identical in all noun classes. It would certainly be inadequate to assume that this is a mere accident. 
I have assumed that Strategy 2 is the result of a reanalysis process that turned relative pronouns in Zulu into relativising clitics. I now suggest that Strategy 2 itself reflects an earlier historical stage in Zulu from which the relative concord strategy (Strategy 1) of modern Zulu has been derived via reanalysis. I assume that at some stage, Zulu, like many other Bantu languages (cf. the examples in (19)-(23)), used demonstratives as relative pronouns in relative clauses. These relative pronouns then became clitics and hence phonologically bound to the first word of the IP. In indirect relatives, this word would typically be the subject noun of the relative clause, as is illustrated by the examples from Strategy 2 presented above. However, in certain syntactic contexts, like e.g., in direct relatives (where the subject position is not filled with phonological material), the phrasal affix would end up adjacent to the predicate of the relative clause. As a clitic, it still needs a phonological host, a function that would then be fulfilled by a verb or an adjective. Crucially, I assume that in these contexts, speakers started to reanalyse the structure with the adjacent relativising clitic and the subject prefix of the relative clause predicate and merged the two into one single element. As such, the former phrase-level affix turned into a genuine word-level affix. This change consequently triggered a change in the agreement properties of the relative marker. Reanalysed as being affixed to a word inside the relative clause, the relative marker no longer expresses a morphosyntactic property of the relative clause (= agreement with the head noun), but a morphosyntactic property of the predicate (= agreement with the subject of the relative clause) - it has become a relative concord.

One advantage of this proposal is that it provides a possible solution to the problem raised by the controversial character of Strategy 2. Strategy 2 is no longer fully productive in modern Zulu. Its rare occurrences can be analysed as relics of an older form which has been pushed aside by the emergence of Strategy 1 in present-day Zulu. In the light of this assumption, dialectal, geographical and generational variation with respect to the acceptability of Strategy 2 is expected - it is not surprising that in some contexts, regions and speaker groups, the older form has been preserved longer than in others.

\section{Conclusion}

The two strategies of relative clause formation in Zulu investigated in this paper show that the same set of relative markers can occur in two different positions. As a relative concord, the relative marker is an inflectional word- 
level prefix; it combines with the predicate of the relative clause and expresses relativisation and agreement between this predicate and the subject. As a phrase-level affix, the same relative marker is attached to the whole relative clause and expresses agreement with the head noun. Since phrasal affixes are clitics, the relative marker needs to attach phonologically to the initial noun of the relative clause, which makes it appear as if the (word-level) relative concord was somehow "misplaced" and attached to a nominal stem. However, I have proposed that the adjacency of relative markers and relative clause initial nouns is in fact a result of a morphological phrase-level rule. If my analysis proves to be correct, then the properties of Zulu relative clauses can be interpreted as evidence for the theory suggested in Anderson (1992). Both clitics and inflectional affixes are phonological reflexes of morphological rules; they differ only with respect to the properties of the host to which they attach.

\section{References}

Alexiadou, Artemis - Paul Law - André Meinunger - Chris Wilder (eds) 2000. The syntax of relative clauses. John Benjamins, Amsterdam \& Philadelphia.

Anderson, Stephen R. 1992. A-morphous morphology. Cambridge University Press, Cambridge.

Chomsky, Noam 1986. Barriers. MIT Press, Cambridge MA.

Chumbow, Beban 1977. Relatives as determiners: a case from Ngemba. In: Paul KoteyHaig Der-Houssikian (eds) Language and linguistic problems in Africa (Proceedings of the Seventh Conference on African Linguistics), 283-302. Hornbeam Press, Columbia.

Colenso, John William 1859. An elementary grammar of the Zulu-Kafir language. Church of England Missions, Ekukanyeni.

Cope, Anthony Trevor 1984. A comprehensive course in the Zulu language. Department of Zulu Language and Literature, University of Natal, Durban.

Doke, Clement Martyn 1954. The southern Bantu languages. Oxford University Press, Oxford.

Du Plessis, Jacobus Albertus - Marianne Visser in prep. Zulu syntax. Unpublished book manuscript. University of Stellenbosch.

Halpern, Aaron 1995. On the placement and morphology of clitics. CSLI Publications, Stanford CA.

Heim, Irene-Angelika Kratzer 1998. Semantics in generative grammar. Blackwell, Cambridge MA \& Oxford.

Kayne, Richard S. 1994. The antisymmetry of syntax. MIT Press, Cambridge MA.

Khumalo, James Steven Mzilikazi 1992. The morphology of the direct relative in Zulu. In: Derek F. Gowlett (ed.) African linguistic contributions, 210-26. Via Afrika Limited, Hatfield. 
Lieber, Rochelle 1992. Deconstructing morphology. Word formation in syntactic theory. The University of Chicago Press, Chicago.

Marantz, Alec 1988. Clitics, morphological merger, and the mapping to phonological structure. In: Mark Hammond - Michael Noonan (eds) Theoretical morphology: approaches in modern linguistics, 253-70. Academic Press, San Diego.

Meinhof, Carl 1906. Grundzüge einer vergleichenden Grammatik der Bantusprachen. Dietrich Reimer, Berlin.

Mischke, Gerda 1998. Southern Sotho verbal relative constructions. In: South African Journal of African Languages 18:106-11.

Pahl, Herbert Walter 1983. IsiXhosa. Educum Publishers, Johannesburg.

Partee, Barbara 1975. Montague Grammar and Transformational Grammar. In: Linguistic Inquiry $6: 203-300$.

Poulos, George 1982. Issues in Zulu relativization. Ph.D. dissertation, Department of African Languages, Rhodes University, Grahamstown, South Africa.

Poulos, George-Christian T. Msimang 1998. A linguistic analysis of Zulu. Via Afrika, Cape Town.

Quine, Willard Van Orman 1960. Word and object. Oxford University Press, Oxford.

Rebuschi, Georges 2002. Generalizing the antisymmetric analysis of coordination to nominal modification. Ms. Paris.

Spuy, Andrew van der 2001. Grammatical structure and Zulu morphology. Ph.D. dissertation, University of the Witwatersrand, Johanessburg.

uNemo no date; 19th century. Igrama lesi ngisi ukuti nje inncwadi yokufundisa abantu ulimi lwabelungu: Inncwadi yokuqala. Durban.

Wald, Benji 1970. Relativization in Umbundu. In: Studies in African Linguistics 1:131-256.

Ziervogel, Dirk-Jacobus A. Louw-Petrus C. Taljaard 1985. A handbook of the Zulu language. J.L. van Schaik, Pretoria.

Zwicky, Arnold M. 1977. On clitics. Indiana University Linguistics Club, Bloomington.

Zwicky, Arnold M.-Geoffrey K. Pullum 1983. Cliticization vs. inflection: English n't. In: Language 59: 502-13.

Address of the author: Jochen Zeller

Linguistics Programme

Faculty of Human Sciences

University of Natal

4041 Durban

South Africa

zeller@nu.ac.za 